\title{
Insult-dependent effect of bone marrow cell therapy on inflammatory response in a murine model of extrapulmonary acute respiratory distress syndrome
}

\author{
Tatiana Maron-Gutierrez ${ }^{1,2,3}$, Johnatas Dutra Silva ${ }^{1}$, Fernanda Ferreira Cruz ${ }^{1}$, Samantha Alegria', \\ Debora Gonçalves Xisto ${ }^{1}$, Edson Fernandes Assis ${ }^{3}$, Hugo Caire Castro-Faria-Neto ${ }^{3}$, Claudia Chimisso Dos Santos ${ }^{4,5}$, \\ Marcelo Marcos Morales ${ }^{2}$ and Patricia Rieken Macedo Rocco ${ }^{1 *}$
}

See related commentary by Pelosi and Sutherasan, http://stemcellres.com/content/4/6/143

\begin{abstract}
Introduction: Administration of bone marrow-derived cells produces beneficial effects in experimental extrapulmonary acute respiratory distress syndrome (ARDS). However, there are controversies regarding the effects of timing of cell administration and initial insult severity on inflammatory response. We evaluated the effects of bone marrow-derived mononuclear cells (BMDMC) in two models of extrapulmonary ARDS once lung morphofunctional changes had already been installed.
\end{abstract}

Methods: BALB/c mice received lipopolysaccharide (LPS) intraperitoneally ( $5 \mathrm{mg} / \mathrm{kg}$ in $0.5 \mathrm{ml}$ saline) or underwent cecal ligation and puncture (CLP). Control mice received saline intraperitoneally $(0.5 \mathrm{ml})$ or underwent sham surgery. At 24 hours, groups were further randomized to receive saline or BMDMC $\left(2 \times 10^{6}\right)$ intravenously. Lung mechanics, histology, and humoral and cellular parameters of lung inflammation and remodeling were analyzed 1 , 3 and 7 days after ARDS induction.

Results: BMDMC therapy led to improved survival in the CLP group, reduced lung elastance, alveolar collapse, tissue and bronchoalveolar lavage fluid cellularity, collagen fiber content, and interleukin-1 $\beta$ and increased chemokine (keratinocyte-derived chemokine and monocyte chemotactic protein-1) expression in lung tissue regardless of the experimental ARDS model. Intercellular adhesion molecule-1 and vascular cell adhesion molecule-1 expression in lung tissue increased after cell therapy depending on the insult (LPS or CLP).

Conclusions: BMDMC therapy at day 1 successfully reduced lung inflammation and remodeling, thus contributing to improvement of lung mechanics in both extrapulmonary ARDS models. Nevertheless, the different inflammatory responses induced by LPS and CLP resulted in distinct effects of BMDMC therapy. These data may be useful in the clinical setting, as they suggest that the type of initial insult plays a key role in the outcome of treatment.

\footnotetext{
* Correspondence: prmrocco@biof.ufrj.br

${ }^{1}$ Laboratory of Pulmonary Investigation, Carlos Chagas Filho Institute of

Biophysics, Federal University of Rio de Janeiro, Avenida Carlos Chagas Filho,

373, Sala G1-014, Cidade Universitária, Rio de Janeiro, RJ, CEP:21.941-902, Brazil

Full list of author information is available at the end of the article
} 


\section{Introduction}

Acute respiratory distress syndrome (ARDS) is a multifaceted syndrome with a wide-ranging clinical phenotype, making it a challenge to translate experimental results into feasible therapies in the clinical setting [1]. Several studies have addressed the therapeutic benefits of bone marrow-derived cells, such as bone marrow-derived mononuclear cells (BMDMCs) and mesenchymal stromal cells, in murine models of extrapulmonary ARDS induced by intraperitoneal administration of Escherichia coli lipopolysaccharide (LPS) [2,3] and cecal ligation and puncture (CLP) [4-6]. Bone marrow-derived cells have been shown to mitigate systemic and pulmonary inflammation, as well as decrease lung edema and enhance bacterial clearance, resulting in lower mortality [2,4-7]. Nevertheless, the potential effects of the severity of ARDS on inflammatory response and the time course for lung damage, which may play a role in the outcome of treatments [8], have not been addressed in the literature. It may also be argued that these effects are mediated by the specific characteristics of different types of injury.

In the present study, the beneficial effects of cell therapy were tested in light of the hypothesis that BMDMCs may exert distinctive effects on lung inflammation and remodeling depending on the initial insult. To this end, murine models of LPS and CLP-induced pulmonary injury [8] were used, and lung mechanics, histology, and humoral and cellular parameters of lung inflammation and remodeling were analyzed at 1, 3 and 7 days after induction of ARDS.

\section{Methods}

This study was approved by the Ethics Committee of the Carlos Chagas Filho Institute of Biophysics, Health Sciences Center, and Federal University of Brazil (CEUA-CCS, IBCCF 019). All animals received humane care in compliance with the Principles of Laboratory Animal Care formulated by the National Society for Medical Research and the Guide for the Care and Use of Laboratory Animals prepared by the US National Academy of Sciences.

\section{Cell isolation}

BMDMCs were isolated from the femurs and tibiae of 8-week-old BALB/c mice as described previously [2]. Briefly, bone marrow cells from male BALB/c mice were flushed from femurs and tibias with Dulbecco's modified Eagle's medium. After a homogeneous cell suspension was achieved, cells were centrifuged $(400 \times g$ for 10 minutes), resuspended in Dulbecco's modified Eagle's medium and added to Ficoll-Hypaque. The isolated cells were counted in a Neubauer chamber with Trypan Blue for evaluation of viability. Saline or BMDMCs were injected into the jugular vein.

\section{Experimental protocol}

BALB/c mice (age 8 to 10 weeks) were used: 98 females and 10 male donors (weight 20 to $25 \mathrm{~g}$ ). Numbers were given to each cage and letters were given to each experimental group for the randomization process, and afterwards each number was linked to a letter. A member of the laboratory that was blind to the experimental procedure performed the randomization process. Animals in the control groups received saline intraperitoneally $(0.5 \mathrm{ml}$, group C) or were subjected to sham surgery (sham group). Mice in the ARDS groups received $E$. coli LPS intraperitoneally $(5 \mathrm{mg} / \mathrm{kg}$ in $0.5 \mathrm{ml}$ saline; LPS group) or underwent CLP (Figure 1). In the CLP groups, polymicrobial sepsis was induced as described previously [8]. Briefly, animals were anesthetized with sevoflurane and a midline laparotomy was performed. The cecum was carefully isolated and a 3-0 cotton ligature was placed below the ileocecal valve to prevent bowel obstruction. Finally, the cecum was punctured twice with an 18-gauge needle [8]. In the sham group, an abdominal incision was made with no cecal ligation and perforation. Both layers of the abdominal cavity were closed with 3.0 silk sutures, followed by fluid resuscitation with $0.5 \mathrm{ml} / 10 \mathrm{~g}$ body weight of prewarmed sterile saline subcutaneously. Sham and CLP animals received tramadol $(0.05 \mathrm{mg} / \mathrm{kg}$ body weight subcutaneously) for postoperative analgesia, repeated every 8 hours. After this step, animals returned to their cages, where they received water and food ad libitum. All manipulations described were performed by the same investigator to ensure consistency. Twenty-four hours after lung injury, animals in group $\mathrm{C}$ and the ARDS group were further randomized to receive saline $(0.05 \mathrm{ml})$ or BMDMCs $(2 \times$ $10^{6}$ BMDMCs in $0.05 \mathrm{ml}$ saline) intravenously. At day 1 , these models had similar degrees of lung mechanical compromise [8].

\section{Lung mechanics}

On days 1, 3 and 7 after induction of ARDS, mice were sedated (diazepam $1 \mathrm{mg}$ intraperitoneally), anesthetized (thiopental sodium $20 \mathrm{mg} / \mathrm{kg}$ intraperitoneally), tracheotomized, paralyzed (vecuronium bromide, $0.005 \mathrm{mg} / \mathrm{kg}$ intravenously), and mechanically ventilated with the following settings: respiratory frequency 100 breaths/minute, tidal volume $0.2 \mathrm{ml}$, and fraction of inspired oxygen 0.21 . The anterior chest wall was surgically removed and a positive end-expiratory pressure of $2 \mathrm{cmH}_{2} \mathrm{O}$ was applied. After a 10-minute ventilation period, lung mechanics were computed. At the end of the experiment (approximately 30 minutes), the lungs were prepared for histology and molecular biology. Airflow, volume and tracheal pressure were measured [9]. In an open chest preparation, tracheal pressure reflects transpulmonary pressure. Static lung elastance (Est,L) was computed 

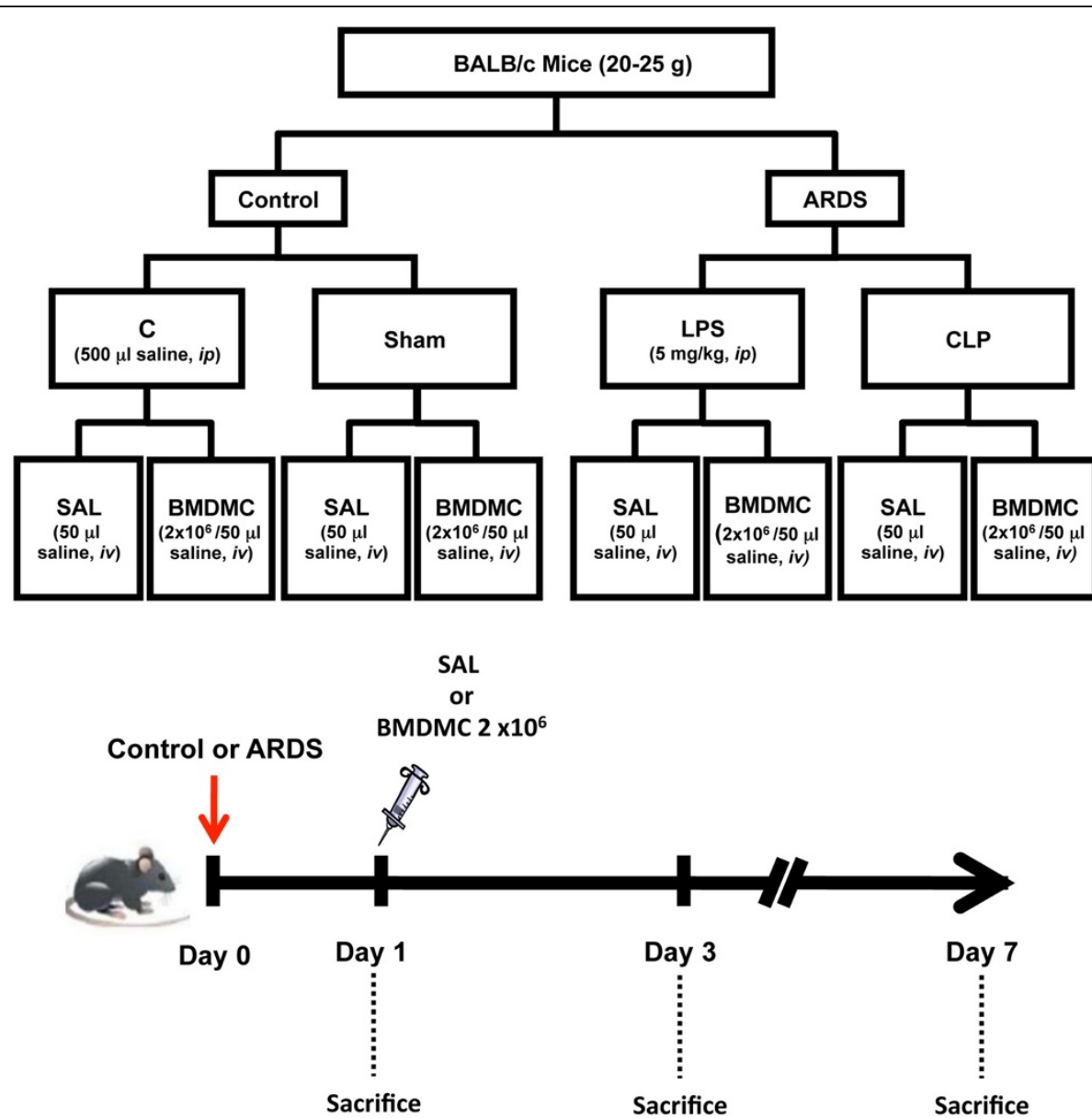

Figure 1 Flowchart and timeline of study design. Control (group C) animals received saline intraperitoneally (ip). LPS group animals received Escherichia coli lipopolysaccharide intraperitoneally. CLP group animals were subjected to cecal ligation and puncture. A sham-operated group was used as control for animals undergoing CLP. At day 1, some animals were sacrificed, post acute respiratory distress syndrome (ARDS), to evaluate lung function and histology, while other animals were further randomized into subgroups to receive saline (SAL) or bone marrowderived mononuclear cells (BMDMCs, $2 \times 10^{6}$ cells) intravenously (iv). Animals were euthanized at days 1, 3 and 7.

using the ANADAT data analysis software (RHTInfoData, Inc., Montreal, Quebec, Canada).

\section{Lung histology}

Laparotomy was performed immediately after determination of lung mechanics. Heparin was injected intravenously, the trachea was clamped at end expiration, and the abdominal aorta and vena cava were sectioned. The right lung was removed, fixed in $4 \%$ buffered formaldehyde, embedded in paraffin, and cut into slices $4 \mu \mathrm{m}$ thick, which were stained with hematoxylin and eosin (Vetec Química Fina, Rio de Janeiro, Brazil).

The volume fraction of collapsed and normal pulmonary areas and the number of macrophages and neutrophils in pulmonary tissue were determined by the point-counting technique at a magnification of $\times 200$ across 10 random, noncoincident microscopic fields [10]. Collagen fibers (picrosirius polarization method) [11] were quantified in the alveolar septa and expressed as the percentage of collagen fibers per tissue area.

\section{Inflammatory mediators and growth factor mRNA expression}

Quantitative real-time reverse transcription polymerase chain reaction was performed to measure the relative levels of mRNA expression of interleukin (IL)-1 $\beta$, IL-6, IL-10, keratinocyte-derived chemokine (KC), monocyte chemotactic protein (MCP)-1, intercellular adhesion molecule (ICAM)-1, vascular cell adhesion molecule (VCAM)-1, and transforming growth factor beta (TGF- $\beta$ ). Slices were obtained from the center of the left lung, collected in cryotubes, quick-frozen by immersion in liquid nitrogen and stored at $-80^{\circ} \mathrm{C}$. Total RNA was extracted from the frozen tissues using the SV Total RNA Isolation System (Promega, Rio de Janeiro, Brazil) according to the manufacturer's instructions. RNA concentrations were measured 
in a Nanodrop- ${ }^{\circledR}$ ND-1000 spectrophotometer (NanoDrop Technologies, Inc. 3411 Silverside Road. Bancroft Building. Wilmington, DE 19810 USA). First-strand cDNA was synthesized from total RNA using the GoTaq ${ }^{\circ}$ 2-Step RTqPCR System (Promega), according to the manufacturer's recommendations. Relative mRNA levels were measured with a SYBR green detection system using a Mastercycler ep realplex ${ }^{2}$ S (Eppendorf, São Paulo, Brazil). All samples were measured in triplicate. The relative amount of expression of each gene was calculated as the ratio of studied gene to a control gene (acidic ribosomal phosphoprotein P0 (36B4)) and expressed as the fold-change relative to their respective control (group $\mathrm{C}$ or sham group).

The following polymerase chain reaction primers were used: IL-1 $\beta$, forward 5'-GTT GAC GGA CCC CAA AAG-3' and reverse 5'-GTG CTG CTG CGA GAT TTG-3', 93 base pairs (bp); IL-6, forward 5'-TCT CTG GGA AAT CGT GGA A-3' and reverse 5' -TCT GCA AGT GCA TCA TCG T-3', 81 bp; IL-10, forward 5' TCC CTG GGT GAG AAG CTG-3' and reverse 5'GCT CCA CTG CCT TGC TCT-3', 91 bp; KC, forward 5'-TGA AGC TCC CTT GGT TCA G-3' and reverse 5'-GGT GCC ATC AGA GCA GTC T-3', 91 bp; MCP1, forward 5'-CTT CTG GGC CTG CTG TTC A-3' and reverse 5 '-CCA GCC TAC TCA TTG GGA TCA3', 127 bp; ICAM-1, forward 5' -CCG CAG GTC CAA TTC ACA CT-3' and reverse 5' -TCC AGC CGA GGA CCA TAC AG-3', 143 bp; VCAM-1, forward 5'-GTG AAG ATG GTC GCC GTC TT-3' and reverse 5'-GGC CAT GGA GTC ACC GAT T-3', 126 bp; TGF- $\beta$, forward 5'-ATA CGC CTG agt GGC TGT C-3' and reverse 5'-GCC CTG TAT TCC GTC TCC T-3', 77 bp; and 36B4 (Rplp0), forward 5'-CAA CCC AGC TCT GGA GAA AC-3' and reverse 5'-GTT CTG AGC TGG CAC AGT GA-3', 150 bp.

\section{Inflammatory mediators and growth factor protein expression}

IL-1 $\beta$, IL-6, IL-10, KC, MCP-1, and TGF- $\beta$ protein expressions were measured with ELISA kits accordingly to the manufacturer's instructions (R\&D Systems, Minneapolis, MN, USA).

\section{Bronchoalveolar lavage fluid}

Bronchoalveolar lavage was carried out in the left lung via a tracheal tube with phosphate-buffered saline solution $(0.5 \mathrm{ml})$ containing ethylenediamine tretraacetic acid (10 mM). Total leukocyte numbers were measured in a Neubauer chamber under light microscopy after diluting the samples in Türk solution ( $2 \%$ acetic acid). Bronchoalveolar lavage fluid was centrifuged at $4^{\circ} \mathrm{C}$ for 10 minutes at $400 \times g$ and the cell pellet resuspended in phosphatebuffered saline for further leukocyte enumeration. The protein concentration was determined by the Bradford method.
Differential cell counts were performed in cytospin smears stained by the May-Grünwald-Giemsa method $[2,3]$.

\section{Statistical analysis}

Comparison between control and sham groups was performed at all endpoints (days 1, 3 and 7) using twoway analysis of variance. Since lung function and histological data were not significantly different at these time points, we decided to show only one control group. Between-group differences were therefore assessed using one-way analysis of variance followed by Bonferroni's post-hoc test. Survival curves were derived by the Kaplan-Meier method and compared by log-rank test. The significance level was set at 5\%. All tests were performed in GraphPad Prism 5.0 (GraphPad Software, San Diego, CA, USA).

\section{Results}

Survival curve

At day 7, the survival rate of groups C, LPS-SAL and LPS-BMDMC was $100 \%$. Similarly, the sham mice survival rate was $100 \%$. The CLP-SAL group had a survival rate of $40 \%$. BMDMC administration improved survival in CLP animals $(70 \%$ at day 7$)(P<0.05)$ (Figure 2$)$. Even though the mortality rate in the LPS-treated and CLPtreated animals was not comparable, the degrees of lung mechanical compromise were similar.

\section{BMDMC administration improved lung mechanics and morphometry in both models of extrapulmonary ARDS} Est,L was higher in LPS animals than in controls on day 1. Nevertheless, Est,L in LPS-SAL mice was not increased compared with controls at days 3 and 7 (Figure 3). Est,L was higher in CLP animals than in sham animals on day 1. Est,L remained elevated in CLP-SAL mice at days 3 and 7. BMDMC administration led to a significant reduction in Est,L at days 3 and 7 (Figure 3).

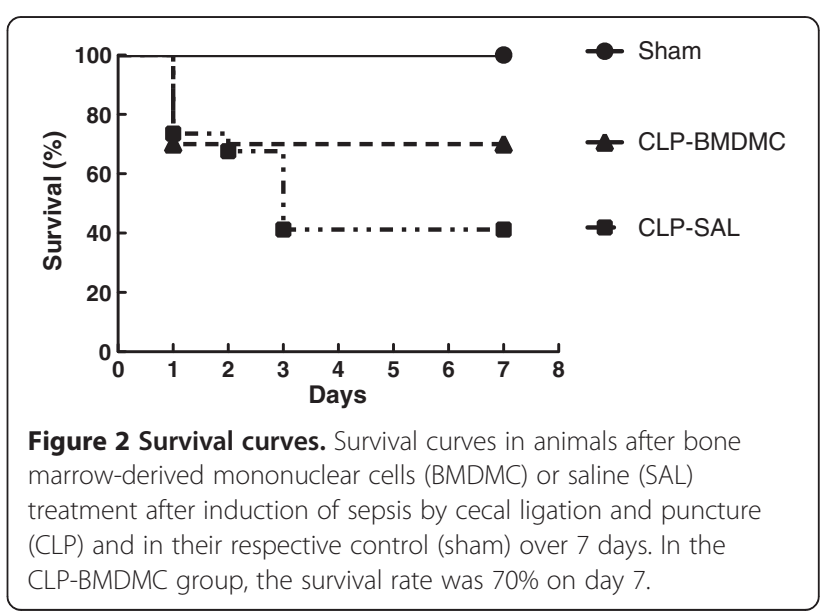




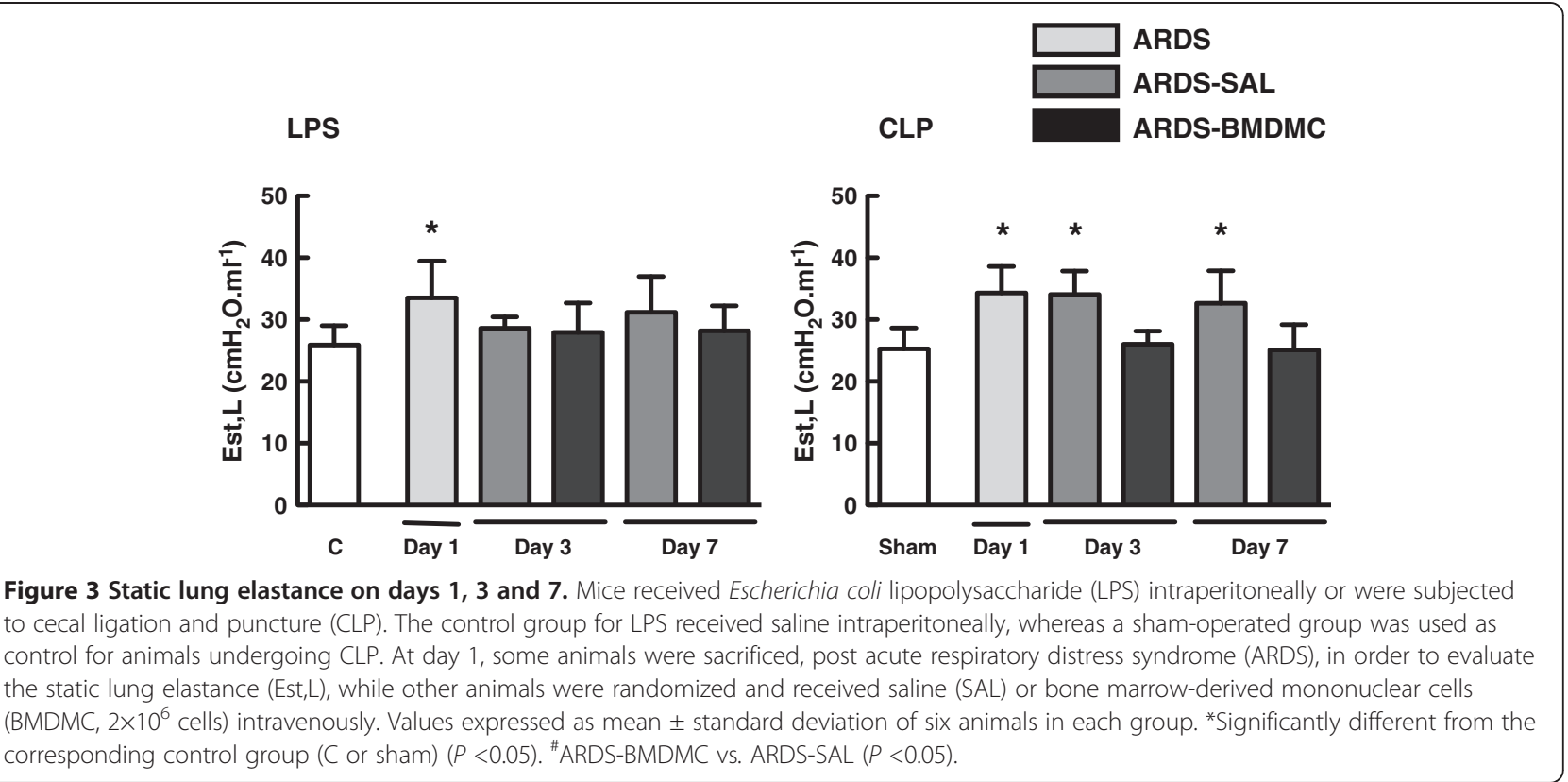

At day 1, both LPS and CLP groups presented interstitial edema, formation of hyaline membrane, neutrophil infiltration and alveolar collapse (Figures 4 and 5). The fraction area of alveolar collapse was higher both in LPS (Figure 4A, Table 1) and in CLP (Figure 5A, Table 1) untreated mice at days 1, 3 and 7. BMDMC administration led to a reduction in alveolar collapse at days 3 and 7, regardless of the initial insult implicated in the pathogenesis of ARDS (Figures 4A and 5A, Table 1).

Neutrophil counts in lung tissue were increased in LPS mice compared with controls at all time points, most prominently on day 1 (Figure 4B). BMDMC administration reduced neutrophils at days 3 and 7 (Figure 4B). Macrophages and total cell counts in lung tissue were increased in LPS mice compared with controls at days 1, 3 and 7 (Figure 4B). Macrophages and total cell counts were decreased in LPS-BMDMC animals at days 3 and 7 (Figure 4B). In untreated CLP mice, the number of neutrophils in lung tissue was higher than in sham mice at all time points, most prominently on day 7 (Figure 5B). BMDMC administration reduced neutrophil counts at day 7 (Figure 5B). Macrophage and total cell counts in lung tissue were higher in CLP mice than in sham mice at days 1,3 and 7 (Figure 5B). BMDMC administration reduced macrophage and total cell counts at days 3 and 7 (Figure 5B).

\section{Effects of BMDMCs on inflammatory mediators in the lung}

The increase in inflammatory cell count in lung tissue was accompanied by a significant increase in lung tissue levels of inflammatory mediator mRNA expression in the saline-treated groups. IL-1 $\beta$ and IL-10 were increased on day 1 in the LPS-SAL group. Nevertheless, this increase was not sustained over time (Figure $4 \mathrm{C}$ ). In CLP-SAL, the increase in IL- $1 \beta$ mRNA expression was observed at a later time point, at days 3 and 7 (Figure 5C). No significant differences were observed in IL-10 mRNA expression in the CLP-SAL group (Figure 5C) and in IL-6 mRNA expression in both CLP and LPS groups. BMDMCs reduced IL-1 $\beta$ mRNA expression in the LPS groups (Figure 4C) and CLP groups (Figure 5C). Levels of MCP-1 and KC mRNA expression were high on day 1 in the LPS-SAL group (Figure 4C), whereas in the CLP-SAL group both $\mathrm{KC}$ and $\mathrm{MCP}-1$ were increased on day 3 (Figure 5C). In LPS-BMDMC mice, cell therapy augmented MCP-1 mRNA expression on day 3 and $\mathrm{KC}$ mRNA expression on day 7 (Figure 4C).

We also analyzed protein expressions of IL-1 $\beta$, IL-6, IL-10, KC and MCP-1. At day 1 there was an increase in IL-1 $\beta, \mathrm{KC}$ and $\mathrm{MCP}-1$ protein expression, while at day 7 there was a decrease in IL-6, IL-10, KC and MCP-1 protein expressions in the LPS-SAL group (Figure 4D). Interestingly, at day $7 \mathrm{BMDMC}$ therapy led to an increase of these mediators' levels compared with LPSSAL, returning to control values (Figure 4D). In the CLP-SAL group, there was an increase in IL- $1 \beta$ and IL10 at days 3 and 7, and in MCP-1 at day 3 (Figure 5D). In CLP-BMDMC mice, cell therapy increased IL-6 expression at day 7, and IL-10 and MCP-1 at days 3 and 7.

\section{Effects of BMDMCs on influx of inflammatory cells and} protein permeability in the alveolus

The increase in lung tissue levels of inflammatory mediators was accompanied by a significant increase in 


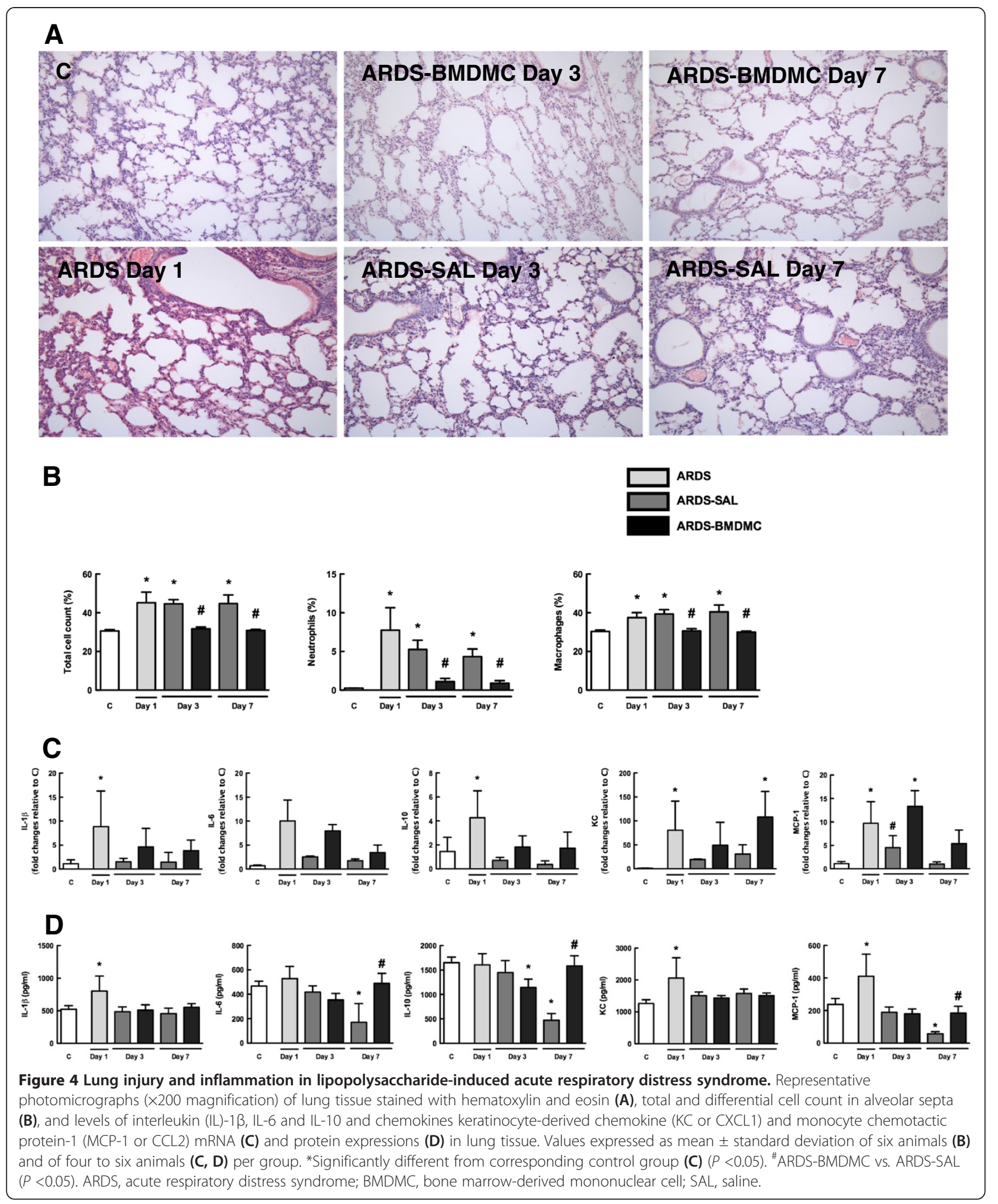

inflammatory cell count in bronchoalveolar lavage fluid (BALF) (Figure 6A,B) and an increase in lung protein permeability (Figure 6C). In LPS groups, the total number of cells in BALF was increased at days 1 and 3 (Figure 6A). BMDMC administration resulted in a decrease in total cell infiltration in BALF. Mononuclear cells were 


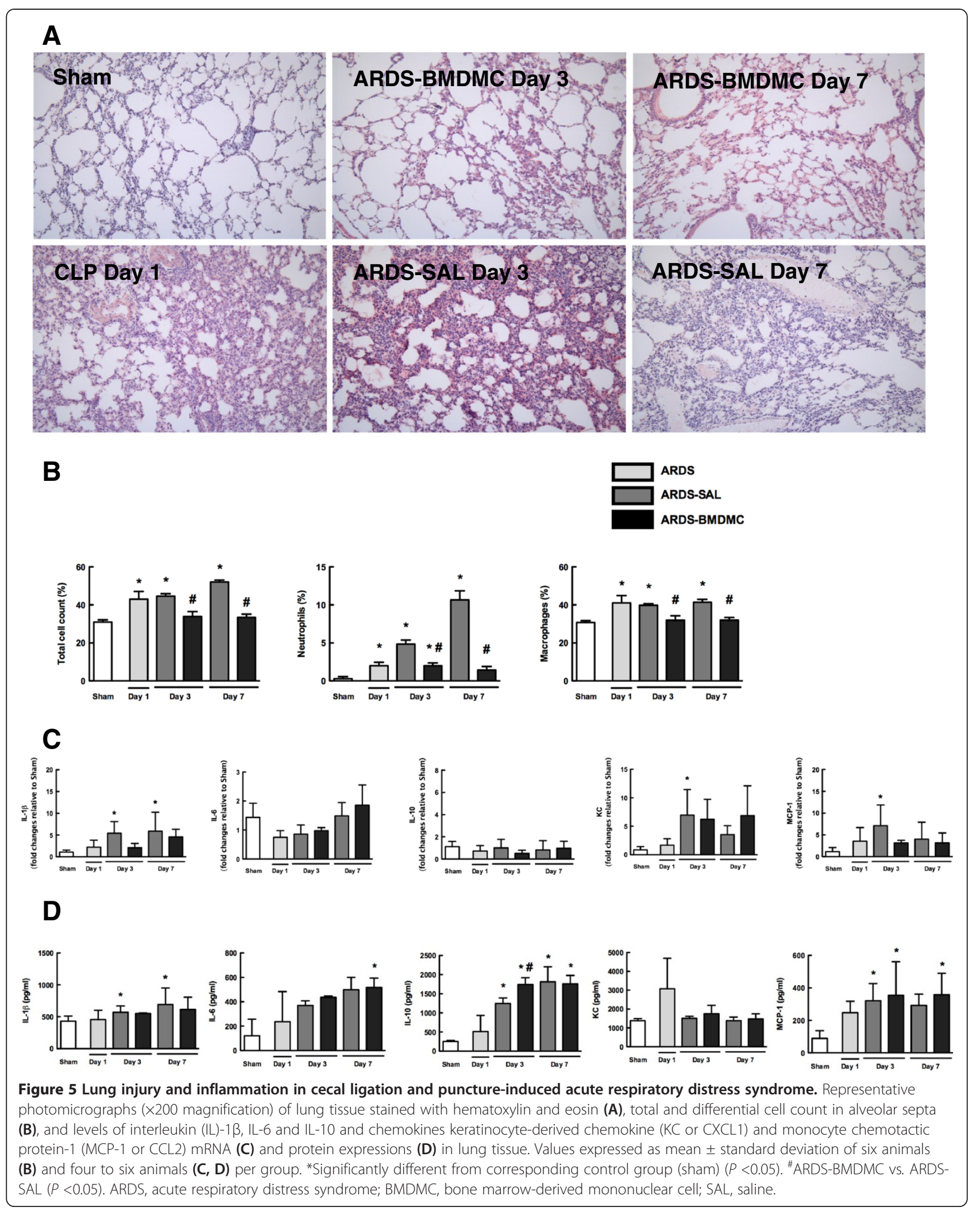


Table 1 Morphometric parameters

\begin{tabular}{|c|c|c|c|c|c|c|c|}
\hline & \multirow[t]{2}{*}{ Group } & \multicolumn{2}{|c|}{ Normal area (\%) } & \multicolumn{2}{|c|}{ Alveolar collapse (\%) } & \multicolumn{2}{|c|}{ Hyperinflation (\%) } \\
\hline & & LPS & CLP & LPS & CLP & LPS & CLP \\
\hline & C (LPS) or sham (CLP) & $99.6 \pm 0.7$ & $99.0 \pm 1.2$ & $0.4 \pm 0.7$ & $1.0 \pm 1.2$ & $0.0 \pm 0.0$ & $0.0 \pm 0.0$ \\
\hline Day 1 & ARDS & $85.0 \pm 7.0^{*}$ & $92.0 \pm 3.3^{*}$ & $13.4 \pm 6.0^{*}$ & $5.6 \pm 4.0^{*}$ & $1.6 \pm 3.0$ & $0.0 \pm 0.0$ \\
\hline \multirow[t]{2}{*}{ Day 3} & ARDS-SAL & $93.5 \pm 2.4^{*}$ & $86.1 \pm 4.2^{*}$ & $6.5 \pm 2.4^{*}$ & $11.0 \pm 1.7^{*}$ & $0.0 \pm 0.0$ & $2.9 \pm 4.2^{*}$ \\
\hline & ARDS-BMDMC & $97.4 \pm 1.5$ & $94.6 \pm 2.5 \#$ & $2.6 \pm 1.5$ & $4.6 \pm 2.4 \#$ & $0.0 \pm 0.0$ & $0.0 \pm 0.0$ \\
\hline \multirow[t]{2}{*}{ Day 7} & ARDS-SAL & $94.0 \pm 1.0^{*}$ & $93.6 \pm 2.9^{*}$ & $4.8 \pm 2.0^{*}$ & $6.5 \pm 2.8^{*}$ & $0.0 \pm 0.0$ & $0.3 \pm 1.2$ \\
\hline & ARDS-BMDMC & $98.8 \pm 0.8$ & $96.8 \pm 2.2$ & $1.2 \pm 0.8$ & $3.2 \pm 2.2$ & $0.0 \pm 0.0$ & $0.0 \pm 0.0$ \\
\hline
\end{tabular}

Mice received Escherichia coli lipopolysaccharide (LPS) intraperitoneally or were subjected to cecal ligation and puncture (CLP) surgery. Control group animals received saline intraperitoneally, whereas a sham-operated group was used as control for animals undergoing CLP. At day 1, some animals were sacrificed, post acute respiratory distress syndrome (ARDS), to evaluate lung morphometry, while other animals were further randomized into subgroups to receive saline (SAL) or bone marrow-derived mononuclear cells (BMDMC, $2 \times 10^{6}$ cells) intravenously. Values expressed as mean \pm standard deviation of sic animals in each group. All values were computed in 10 random, noncoincident fields per animal. *Significantly different from corresponding control group (control or sham) $(P<0.05)$. ${ }^{\#}$ ARDS-BMDMC vs. ARDS-SAL $(P<0.05)$.

increased at days 1 and 3 , without significant differences in polymorphonuclear cell count (Figure 6A). In CLP groups there was an increase in the cell influx at day 3, both mononuclear cells and polymorphonuclear cells (Figure 6B). BMDMC therapy reduced mononuclear and polymorphonuclear cell influx at day 3 (Figure 6B).

\section{Effects of BMDMCs on pulmonary adhesion molecule mRNA expression are dependent on the initial insult} Levels of ICAM-1 and VCAM-1 mRNA expression were high on day 1 in the LPS-SAL group (Figure 7), whereas in the CLP-SAL group these adhesion molecules were increased on day 3 (Figure 7). In LPS-BMDMC mice, cell therapy increased ICAM-1 mRNA expression on day 7 (Figure 7), with no significant differences in VCAM-1 mRNA expression; however, in CLP-BMDMC mice, VCAM-1 was increased on day 7 (Figure 8), without any increase in ICAM-1 mRNA expression.

\section{BMDMCs reduced collagen fiber content in the lung parenchyma}

Both LPS-SAL and CLP-SAL mice had increased collagen fiber content at days 3 and 7 (Figure 8). BMDMC administration led to a significant decrease in collagen content; nevertheless, these changes in lung parenchyma were not associated with TGF- $\beta$ mRNA and protein expression in lung tissue (Figure 8).

\section{Discussion}

In the present study, in support of our initial hypothesis, BMDMC administration had distinct effects on adhesion molecule mRNA expression levels depending on the primary insult, resulting in an increase in ICAM-1 after LPSinduced ARDS, while increasing VCAM-1 levels after CLP-induced ARDS at day 7. This is the first study to compare cell therapy effects in two different experimental models of extrapulmonary ARDS (LPS and CLP). In previous studies from our group [2,3] we observed that cell therapy had distinct effects on lung inflammation and remodeling depending on ARDS etiology (pulmonary vs. extrapulmonary). In this context, we hypothesized that even in the same etiology of ARDS, depending on the primary insult (LPS and CLP), cell therapy could have beneficial yet distinct effects. Demonstrating this hypothesis, in the clinical scenario when patients are treated according to ARDS etiology (pulmonary vs. extrapulmonary), we should be aware of therapy effects, since there may be different outcomes related to lung inflammation and remodeling.

In previous studies with LPS-induced ARDS [2,7,12,13] and CLP-induced ARDS [4-6], bone marrow cells were administered only a few hours after injury. This administration limits the applicability of results to clinical practice, because the time course for lung damage is not taken into consideration. In order to produce a more clinically relevant scenario, in the present study BMDMCs were injected intravenously 1 day after the initial insult (LPS or CLP), once the lung mechanical and morphologic changes had already been established $[6,8,14,15]$. The effects of BMDMC therapy were evaluated at days 3 and 7 . We are aware that most previous studies of ARDS have used mesenchymal stromal cells; nevertheless, mesenchymal stromal cells require culture conditions that are detrimental for cell transplantation and pose a risk of contamination and immunological reactions. Bearing these limitations in mind, and on the basis of some promising results from previous research conducted by our group $[2,6,12,16,17]$, we employed BMDMCs because they can be easily and safely administered on the day of harvest and are known to reduce lung inflammation and fibrogenesis and thus restore lung function $[2,6,12,17,18]$. Because it has already been demonstrated that stem cell engraftment is not required for 


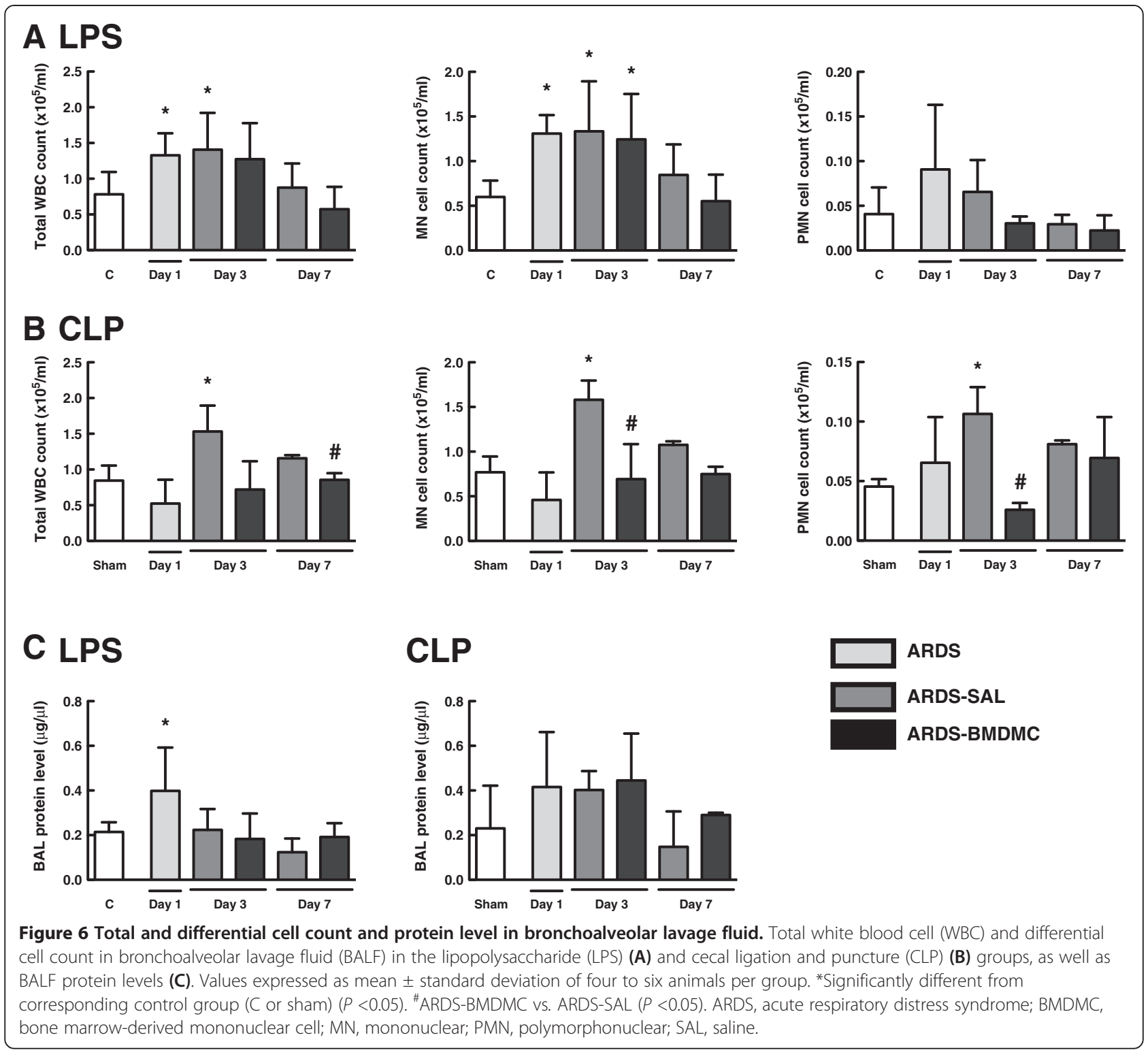

BMDMCs to exert their beneficial effects $[2,4,6,16,17]$, we did not address this issue.

Several studies have suggested that the endothelium plays an important role in the pathophysiology of sepsis [19]. Our results suggest endothelial cell activation by increased expression of cell adhesion molecules and increased production of cytokines. Adhesion molecules (ICAM-1 and VCAM-1) of endothelial cells interact with integrins expressed on neutrophils that stabilize cell-cell interactions, providing firm adherence and thus facilitating cell transmigration [20]. ICAM-1 mRNA expression increased after intratracheal administration of endotoxin or CLP-induced ARDS, in accordance with previous studies [21-23]. Nevertheless, despite the increase in mRNA expression of ICAM-1 and VCAM-1 as well as chemokines (MCP-1 and $\mathrm{KC}$ ), BMDMC administration resulted in fewer mononuclear and polymorphonuclear cells within the lung parenchyma. Nevertheless, we observed an increase in BALF mononuclear cells in both LPS-SAL and LPS-BMDMC groups at day 3. Additionally, when $\mathrm{KC}$ protein expression was analyzed we did not observe an increase after BMDMC therapy, in accordance with our polymorphonuclear cell count findings.

BMDMC administration reined in the inflammatory process, reducing inflammatory cell counts and modulating the levels of inflammatory mediators (such as IL-1 $\beta$ and IL-10) in lung tissue. IL-10 appears to play a pivotal role in controlling the magnitude of inflammatory 


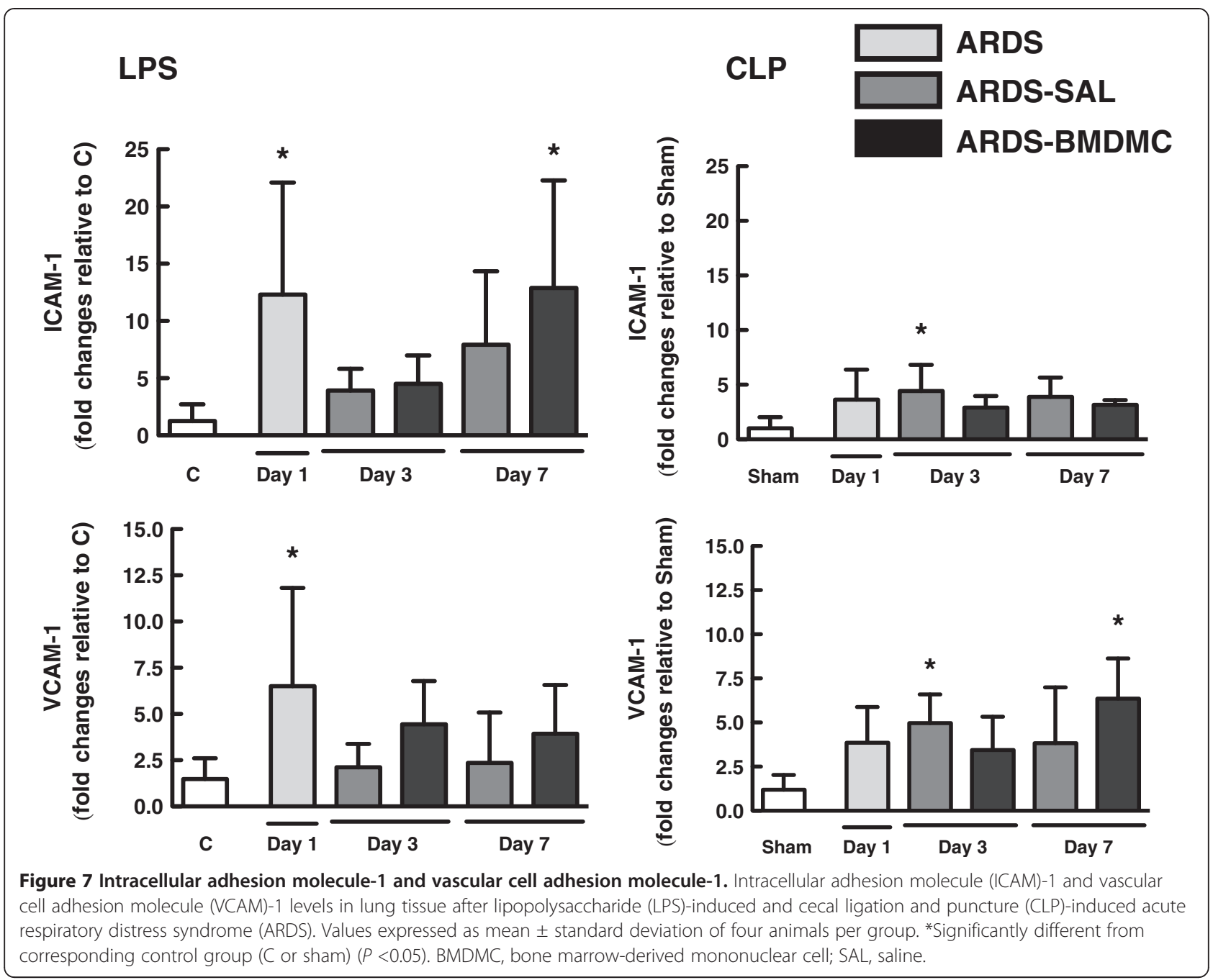

responses during either systemic or pulmonary inflammation, and has been proposed as a key mediator of beneficial effects in CLP-induced experimental sepsis [5]. Nevertheless, other studies investigating bone marrow cell therapy, including those previously conducted by our group, suggest that the beneficial effects of BMDMC extend beyond an effect on a single mediator $[2,4,6]$. IL- $1 \beta$ is mainly produced by activated macrophages as a pro-peptide and is cleaved by caspase- 1 within the inflammasome into an active enzyme [24]. IL-1 $\beta$ can upregulate cell-surface expression of leukocyte and vascular adhesion molecules and stimulate the production of chemokines required for leukocyte recruitment and activation [25]. Increased levels of IL-1 $\beta$ in ARDS patients correlate with development of pulmonary fibrosis $[17,26]$. In this context, we observed that BMDMC decreased lung collagen fiber content both in the LPS and CLP groups. Nevertheless, this reduction was not associated with differences in TGF- $\beta$ mRNA and protein expressions in lung tissue, suggesting another signaling pathway (for example, collagenases) [3].

Studies using endotoxin models for the induction of sepsis have provided a wealth of important knowledge. Nevertheless, the clinical relevance of the LPS experimental model has been questioned, as administration of a bolus of endotoxins does not reflect the complex pathophysiology of sepsis [27]. Alternative experimental models of sepsis have thus been proposed [28], such as CLP, a model of polymicrobial sepsis $[27,29,30]$. Polymicrobial sepsis and endotoxemia have been reported to have differing temporal cytokine responses, innate defense mechanisms, and signaling molecules involved [31], which is consistent with our findings. Additionally, as recently defined by the American Thoracic Society [32], the diagnosis of ARDS in animals should be based on at least three of four main features of evidence: histology, inflammation, physiological dysfunction, and permeability. Our experimental models of LPS and CLP produced histological 


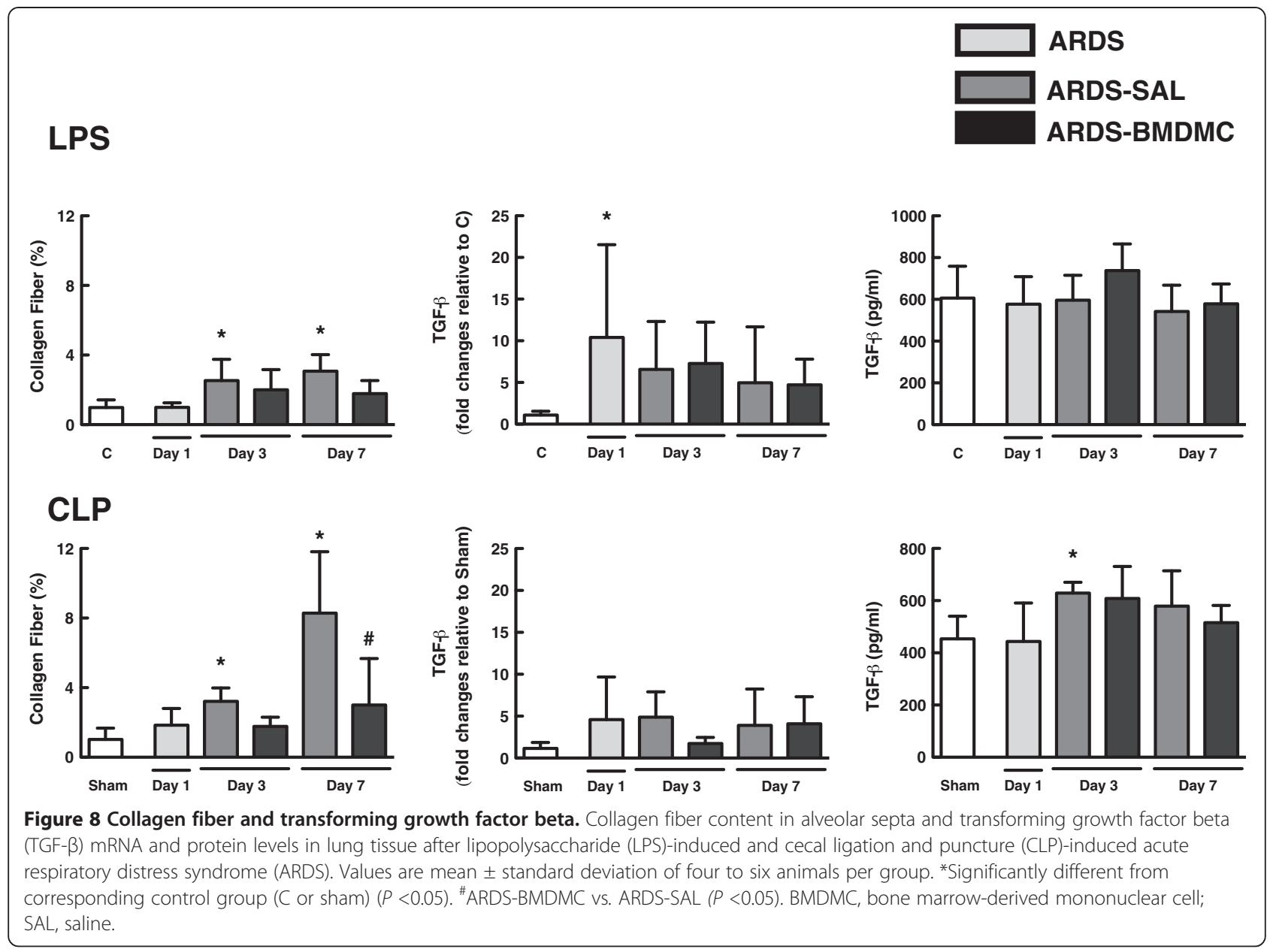

evidence of lung injury, inflammatory response and physiological dysfunction, meeting the American Thoracic Society criteria.

In this context, our study has some limitations. First, mortality was higher in the ARDS-CLP group (60\%) than in the ARDS-LPS group (0\%). Second, the CLP model is one in which there is an ongoing septic insult, with worsening injury over time. In contrast, the LPS model is one of a single insult, making it difficult to compare BMDMC effects across models. We plan future studies to compare the BMDMC therapy in two bacterial (septic) models. Third, inflammatory mediators were measured in lung tissue. The balance between local and systemic inflammation was therefore not evaluated. Fourth, collagen fiber content was evaluated using a histology technique, but future studies should be performed using either hydroxyproline or soluble collagen assay. Fifth, the study endpoint was 7 days after LPS administration or CLP for induction of ARDS. Nonetheless, to better evaluate the effects of BMDMC therapy on lung inflammation and remodeling, further studies of later time points would be interesting. Sixth, previous studies have used fibroblasts as control cells for cell therapy studies [7,13,33]; however, some have demonstrated that administration of fibroblasts, mesenchymal cells without stem cell properties, may not only be ineffective but may worsen injury $[7,13,33,34]$. Accordingly, saline was chosen as the control. Finally, the effects of BMDMCs on adhesion molecules might be of interest; however, further research, such as the use of knockout mice, is required to assess this issue.

\section{Conclusions}

Specific beneficial effects of BMDMC therapy were observed for each type of initial insult triggering extrapulmonary ARDS. BMDMC therapy at day 1, once lung mechanical and histological changes had already been installed in ARDS, successfully reduced inflammation and remodeling in both extrapulmonary ARDS models. These data may be useful in the clinical setting, as they suggest that the type of insult plays an essential role in the outcome of ARDS treatment. 


\section{Abbreviations}

ARDS: Acute respiratory distress syndrome; BALF: Bronchoalveolar fluid lavage fluid; BMDMC: Bone marrow-derived mononuclear cell; bp: Base pairs; CLP: Cecal ligation and puncture; Est,L: Static lung elastance; ICAM1: Intracellular adhesion molecule-1; IL: Interleukin; KC: Keratinocyte-derived chemokine; LPS: Lipopolysaccharide; MCP-1: Monocyte chemotactic protein-1; TGF- $\beta$ : Transforming growth factor beta; VCAM-1: Vascular cell adhesion molecule-1.

\section{Competing interests}

The authors declare that they have no competing interests.

\section{Authors' contributions}

TM-G made substantial contributions to the conception and design of the study, carried out the study, performed all animal experiments and collected all data, performed the statistical analysis, and drafted the manuscript. JDS measured inflammatory mediator, growth factor mRNA expression, BALF measurements, and drafted the manuscript. FFC and SA performed the histological analysis and drafted the manuscript. DGX made substantial contributions to the conception and design of the study, co-supervised the study, performed animal experiments and corrected the manuscript. EFA performed enzyme-linked immunosorbent assay experiments. HCC-F-N, CCDS, MMM and PRMR made substantial contributions to the conception and design and supervised the conduct of the study, and writing of the article. All authors read and approved the final manuscript.

\section{Acknowledgments}

The authors would like to express their gratitude to Mr Andre Benedito da Silva for animal care, Mrs Ana Lucia Neves da Silva for her help with microscopy, and Scientific Linguagem and Mrs Moira Elizabeth Schöttler for their assistance in editing the manuscript. This work was supported by the Canadian Institutes of Health Research (MOP106545 to CCDS), the Ontario Thoracic Society (OTS2010/2011, to CCDS), the Physicians Services Incorporate (PSI 09-21, to CCDS), the Centers of Excellence Program (PRONEX-FAPERJ, to MMM and PRMR), the Brazilian Council for Scientific and Technological Development (CNPq, to TM-G, JDS, FFC, EFA, HCC-F-N, MMM and PRMR), Coordination for the Improvement of Higher Education Personnel (CAPES, to TM-G, JDS, FFC and PRMR), Rio de Janeiro State Research Supporting Foundation (FAPERJ, to TM-G, DGX, EFA, HCC-F-N, MMM and PRMR), and INCT-INOFAR (to PRMR), Coordination Theme 1 (Health) of the European Community's FP7. Grant agreement number HEALTH-F4-2011-282095 (TARKINAID, to HCC-F-N and PRMR) and Fundação Oswaldo Cruz (FIOCRUZ, to EFA and HCC-F-N).

\section{Author details}

'Laboratory of Pulmonary Investigation, Carlos Chagas Filho Institute of Biophysics, Federal University of Rio de Janeiro, Avenida Carlos Chagas Filho, 373, Sala G1-014, Cidade Universitária, Rio de Janeiro, RJ, CEP:21.941-902, Brazil. ' Laboratory of Cellular and Molecular Physiology, Carlos Chagas Filho Institute of Biophysics, Federal University of Rio de Janeiro, Rio de Janeiro, RJ Brazil. ${ }^{3}$ Laboratory of Immunopharmacology, Oswaldo Cruz Institute, FIOCRUZ, Rio de Janeiro, Avenida Brasil 4365, Pavilhão Ozório de Almeida, sala 16, RJ, CEP. 21040-900, Brazil. ${ }^{4}$ The Keenan Research Centre of the Li Ka Shing Knowledge Institute of St. Michael's Hospital, 30 Bond Street, M5B 1W8, Toronto, Ontario, Canada. ${ }^{5}$ Interdepartmental Division of Critical Care, University of Toronto, St. Michael's Hospital, 30 Bond St., Toronto, Ontario, M5B 1W8, Canada.

Received: 14 May 2013 Revised: 15 September 2013

Accepted: 3 October 2013 Published: 13 October 2013

\section{References}

1. Matthay MA, Ware LB, Zimmerman GA: The acute respiratory distress syndrome. J Clin Invest 2012, 122:2731-2740.

2. Araujo IM, Abreu SC, Maron-Gutierrez T, Cruz F, Fujisaki L, Carreira H Jr, Ornellas F, Ornellas D, Vieira-de-Abreu A, Castro-Faria-Neto HC, Muxfeldt Ab'Saber A, Teodoro WR, Diaz BL, Peres Dacosta C, Capelozzi VL, Pelosi P, Morales MM, Rocco PR: Bone marrow-derived mononuclear cell therapy in experimental pulmonary and extrapulmonary acute lung injury. Crit Care Med 2010, 38:1733-1741.
3. Maron-Gutierrez T, Silva JD, Asensi KD, Bakker-Abreu I, Shan Y, Diaz BL, Goldenberg RC, Mei SH, Stewart DJ, Morales MM, Rocco PR, Dos Santos CC: Effects of mesenchymal stem cell therapy on the time course of pulmonary remodeling depend on the etiology of lung injury in mice. Crit Care Med 2013 [Epub ahead of print].

4. Mei SH, Haitsma JJ, Dos Santos CC, Deng Y, Lai PF, Slutsky AS, Liles WC, Stewart DJ: Mesenchymal stem cells reduce inflammation while enhancing bacterial clearance and improving survival in sepsis. Am J Respir Crit Care Med 2010, 182:1047-1057.

5. Nemeth K, Leelahavanichkul A, Yuen PS, Mayer B, Parmelee A, Doi K, Robey PG, Leelahavanichkul K, Koller BH, Brown JM, Hu X, Jelinek I, Star RA, Mezey E: Bone marrow stromal cells attenuate sepsis via prostaglandin $\mathrm{E}(2)$-dependent reprogramming of host macrophages to increase their interleukin-10 production. Nat Med 2009, 15:42-49.

6. Ornellas DS, Maron-Gutierrez T, Ornellas FM, Cruz FF, Oliveira GP, Lucas $\| \mathrm{H}$ Fujisaki L, Oliveira MG, Teodoro WR, Capelozzi VL, Pelosi P, Morales MM, Rocco PR: Early and late effects of bone marrow-derived mononuclear cell therapy on lung and distal organs in experimental sepsis. Respir Physiol Neurobiol 2011, 178:304-314.

7. Mei SH, McCarter SD, Deng Y, Parker CH, Liles WC, Stewart DJ: Prevention of LPS-induced acute lung injury in mice by mesenchymal stem cells overexpressing angiopoietin 1. PLoS Med 2007, 4:e269.

8. Chao MC, Garcia CS, de Oliveira MB, Santos RS, Lucas IH, Silva PL, VieiraAbreu A, de Castro-Faria-Neto HC, Parra-Cuentas ER, Capelozzi VL, Pelosi P, Rocco PR: Degree of endothelium injury promotes fibroelastogenesis in experimental acute lung injury. Respir Physiol Neurobiol 2010, 173:179-188.

9. Leite-Junior JH, Garcia CS, Souza-Fernandes AB, Silva PL, Ornellas DS, Larangeira AP, Castro-Faria-Neto HC, Morales MM, Negri EM, Capelozzi VL, Zin WA, Pelosi P, Bozza PT, Rocco PR: Methylprednisolone improves lung mechanics and reduces the inflammatory response in pulmonary but not in extrapulmonary mild acute lung injury in mice. Crit Care Med 2008, 36:2621-2628.

10. Weibel ER: Morphometry: stereological theory and practical methods. In Models of Lung Disease - Microscopy and Structural Methods. Edited by Dekker GJNY. Dekker: New York, NY, USA; 1990:199-247.

11. Montes GS: Structural biology of the fibres of the collagenous and elastic systems. Cell Biol Int 1996, 20:15-27.

12. Prota LF, Lassance RM, Maron-Gutierrez T, Castiglione RC, Garcia CS, Santana MC, Souza-Menezes J, Abreu SC, Samoto V, Santiago MF, Capelozzi VL, Takiya CM, Rocco PR, Morales MM: Bone marrow mononuclear cell therapy led to alveolar-capillary membrane repair improving lung mechanics in endotoxin-induced acute lung injury. Cell Transplant 2010, 19:965-971.

13. Gupta N, Su X, Popov B, Lee JW, Serikov V, Matthay MA: Intrapulmonary delivery of bone marrow-derived mesenchymal stem cells improves survival and attenuates endotoxin-induced acute lung injury in mice. J Immunol 2007, 179:1855-1863.

14. Menezes SL, Bozza PT, Neto HC, Laranjeira AP, Negri EM, Capelozzi VL, Zin WA Rocco PR: Pulmonary and extrapulmonary acute lung injury: inflammatory and ultrastructural analyses. J Appl Physiol 2005, 98:1777-1783.

15. Santos FB, Nagato LK, Boechem NM, Negri EM, Guimaraes A, Capelozzi VL, Faffe DS, Zin WA, Rocco PR: Time course of lung parenchyma remodeling in pulmonary and extrapulmonary acute lung injury. J Appl Physiol 2006, 100:98-106.

16. Abreu SC, Antunes MA, Maron-Gutierrez T, Cruz FF, Carmo LG, Ornellas DS Junior HC, Absaber AM, Parra ER, Capelozzi VL, Morales MM, Rocco PR: Effects of bone marrow-derived mononuclear cells on airway and lung parenchyma remodeling in a murine model of chronic allergic inflammation. Respir Physiol Neurobiol 2010, 175:153-163.

17. Maron-Gutierrez T, Castiglione RC, Xisto DG, Oliveira MG, Cruz FF, Pecanha R, Carreira-Junior H, Ornellas DS, Moraes MO, Takiya CM, Rocco PR, Morales MM: Bone marrow-derived mononuclear cell therapy attenuates silicainduced lung fibrosis. Eur Respir J 2011, 37:1217-1225.

18. Nandra KK, Takahashi K, Collino M, Benetti E, Wong WS, Goh FY, Suzuki K, Patel NS, Thiemermann C: Acute treatment with bone marrow-derived mononuclear cells attenuates the organ injury/dysfunction induced by hemorrhagic shock in the rat. Shock 2012, 37:592-598.

19. Aird WC: The role of the endothelium in severe sepsis and multiple organ dysfunction syndrome. Blood 2003, 101:3765-3777.

20. Orfanos SE, Mavrommati I, Korovesi I, Roussos C: Pulmonary endothelium in acute lung injury: from basic science to the critically ill. Intensive Care Med 2004, 30:1702-1714 
21. Zhang H, Zhi L, Moochhala SM, Moore PK, Bhatia M: Endogenous hydrogen sulfide regulates leukocyte trafficking in cecal ligation and puncture-induced sepsis. J Leukoc Biol 2007, 82:894-905.

22. Basit A, Reutershan J, Morris MA, Solga M, Rose CE Jr, Ley K: ICAM-1 and LFA-1 play critical roles in LPS-induced neutrophil recruitment into the alveolar space. Am J Physiol Lung Cell Mol Physiol 2006, 291:L200-L207.

23. Kandasamy K, Sahu G, Parthasarathi K: Real-time imaging reveals endothelium-mediated leukocyte retention in LPS-treated lung microvessels. Microvasc Res 2012, 83:323-331.

24. Dinarello CA: Immunological and inflammatory functions of the interleukin-1 family. Annu Rev Immunol 2009, 27:519-550.

25. Deng JC, Standiford TJ: Growth factors and cytokines in acute lung injury. Compr Physiol 2011, 1:81-104

26. Ortiz LA, Dutreil M, Fattman C, Pandey AC, Torres G, Go K, Phinney DG: Interleukin 1 receptor antagonist mediates the antiinflammatory and antifibrotic effect of mesenchymal stem cells during lung injury. Proc Natl Acad Sci U S A 2007, 104:11002-11007.

27. Remick DG, Newcomb DE, Bolgos GL, Call DR: Comparison of the mortality and inflammatory response of two models of sepsis: lipopolysaccharide vs. cecal ligation and puncture. Shock 2000, 13:110-116.

28. Schultz MJ, van der Poll T: Animal and human models for sepsis. Ann Med 2002, 34:573-581.

29. Bauer P, Lush CW, Kvietys PR, Russell JM, Granger DN: Role of endotoxin in the expression of endothelial selectins after cecal ligation and perforation. Am J Physiol Regul Integr Comp Physiol 2000, 278:R1140-R1147.

30. Echtenacher B, Freudenberg MA, Jack RS, Mannel DN: Differences in innate defense mechanisms in endotoxemia and polymicrobial septic peritonitis. Infect Immun 2001, 69:7271-7276.

31. Patel KN, Soubra SH, Lam FW, Rodriguez MA, Rumbaut RE: Polymicrobial sepsis and endotoxemia promote microvascular thrombosis via distinct mechanisms. J Thromb Haemost 2010, 8:1403-1409.

32. Matute-Bello G, Downey G, Moore BB, Groshong SD, Matthay MA, Slutsky AS, Kuebler WM, Acute Lung Injury in Animals Study Group: An official American Thoracic Society workshop report: features and measurements of experimental acute lung injury in animals. Am J Respir Cell Mol Biol 2011, 44:725-738.

33. Xu J, Woods CR, Mora AL, Joodi R, Brigham KL, lyer S, Rojas M: Prevention of endotoxin-induced systemic response by bone marrow-derived mesenchymal stem cells in mice. Am J Physiol Lung Cell Mol Physiol 2007, 293:L131-L141.

34. Sun CK, Chang LT, Sheu JJ, Chiang CH, Lee FY, Wu CJ, Chua S, Fu M, Yip HK: Bone marrow-derived mononuclear cell therapy alleviates left ventricular remodeling and improves heart function in rat-dilated cardiomyopathy. Crit Care Med 2009, 37:1197-1205.

\section{doi:10.1186/scrt334}

Cite this article as: Maron-Gutierrez et al:: Insult-dependent effect of bone marrow cell therapy on inflammatory response in a murine model of extrapulmonary acute respiratory distress syndrome. Stem Cell Research \& Therapy 2013 4:123.

\section{Submit your next manuscript to BioMed Central and take full advantage of:}

- Convenient online submission

- Thorough peer review

- No space constraints or color figure charges

- Immediate publication on acceptance

- Inclusion in PubMed, CAS, Scopus and Google Scholar

- Research which is freely available for redistribution 